\title{
RESEÑAS LIBROS Y REVISTAS
}

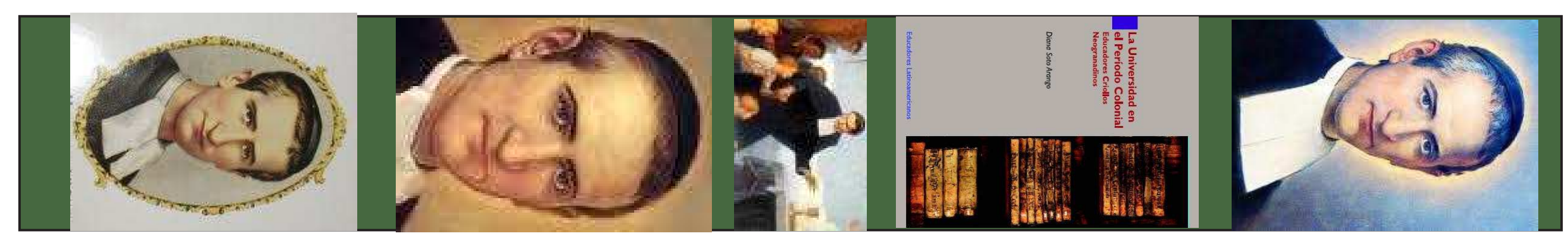


SOTO ARANGO, Diana. (2011): La universidad en el período colonial. Educadores criollos neogranadinos. Tomo II. Tunja, COLCIENCIAS, Dirección de Investigaciones. DIN, Universidad Pedagógica y Tecnológica de Colombia, Doctorado Ciencias de la Educación de RUDECOLOMBIA, HISULA, SHELA, Doce Calles. ISBN: 978-958-660-177, p. 268.

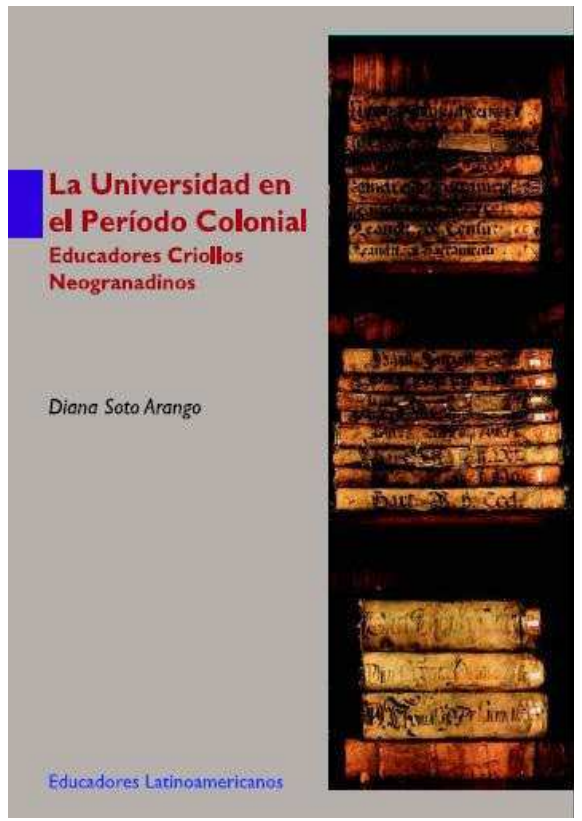

La profesora Diana Soto Arango nos entrega su última investigación sobre La Universidad en el Período Colonial, centrada en la historia de la universidad en el Nuevo Reino de Granada y los planes de reforma universitaria, elaborados por cuatro educadores criollos, neogranadinos e ilustrados, presentados ante las autoridades coloniales, al final del siglo XVIII y comienzos del XIX.

La autora es Doctora en Filosofía y Ciencias de la Educación (UNED, España, 1987) y realizó estudios de Posdoctorado en el Consejo Superior de Investigaciones Científicas de España (CSIC, 1992-1993). Actualmente es profesora de la Universidad Pedagógica y Tecnológica de Colombia y Directora Académica Nacional del Doctorado en Ciencias de la Educación de RUDECOLOMBIA. Coordina dos grupos de investigación: "Historia y Prospectiva de la Universidad Latinoamericana" y "La Ilustración en América Colonial". Directora de la Revista de Historia de la Educación Latinoamericana, miembro de la Sociedad de Historia de la Educación Latinoamericana, autora de 22 libros y múltiples artículos y ponencias sobre historia de la educación, tema al que se ha dedicado desde 1982.

El tema central del libro es determinar el impacto de la universidad colonial, neogranadina, en la formación de identidad y en la construcción de la nación colombiana. El hilo conductor de los diferentes capítulos es el grado de autonomía administrativa, académica y financiera que tuvieron 
estas universidades. El marco de referencia teórico es la Ilustración del siglo XVIII. La nueva mirada que se da a la universidad colonial se enfoca en los educadores criollos ilustrados. La corriente historiográfica en la que se inscribe este trabajo es la historia social de la educación, en la que confluyen la historia estructural, la historia de la sociedad y la historia de la vida cotidiana. Las fuentes y bibliografía se incluyen en un capítulo aparte, en el que se destacan los archivos españoles y colombianos consultados por la autora, al igual que los periódicos, las propuestas de reforma y planes de estudio elaborados por los cuatro educadores seleccionados y un listado de documentos relativos a esos educadores. Además una bibliografía general sobre la Ilustración, la universidad medieval y de América colonial. Los anexos incluyen la cronología detallada sobre la vida de los cuatro educadores estudiados y la transcripción de cinco documentos relativos a los proyectos de reforma planteados por Antonio Moreno y Escandón, Juan Eloy Valenzuela y Mantilla, José Félix de Restrepo y Francisco Antonio Zea. Finalmente el libro incluye 56 ilustraciones, que permiten identificar a las personas e instituciones nombradas.

El libro tiene dos partes. En la primera se presentan los orígenes de la universidad en Occidente, destacando las de Bolonia, París, Alcalá y Salamanca para ver su influencia en las universidades fundadas en los dominios españoles del Nuevo Mundo: México, Lima y el Nuevo Reino de Granada. En éste último enumera cuatro universidades menores: la de los dominicos, jesuitas, agustinos y franciscanos, que funcionaban en Santafé, junto con el Colegio Mayor de Nuestra Señora del Rosario. Fuera de la capital del virreinato incluye el Colegio Seminario de Popayán y el Colegio Universidad de San Pedro Apóstol en Mompox.

Respecto del grado de autonomía de estos centros de estudio, la autora concluyó que hasta 1767, año en que la Corona expulsó a los jesuitas de todos sus dominios, las universidades tuvieron autonomía académica para establecer sus planes y programas, acordes con el modelo universitario de cada una de las órdenes religiosas que las regentaba, pero no tuvieron autonomía interna, por cuanto los provinciales de esas órdenes nombraban los rectores y profesores, sin consultar a los catedráticos ni a los estudiantes. Sin embargo, gozaron de autonomía financiera para organizar y disponer de sus bienes y patrimonio.

Después de 1767, los gobernantes ilustrados del Nuevo Reino de Granada adelantaron una profunda reforma educativa y establecieron escuelas públicas adscritas a los cabildos. El sector civil intentó controlar la educación superior y crear la universidad pública. El Fiscal Moreno y Escandón logró que se aprobara su plan, que estuvo vigente durante escasos seis años (1774-1779). Este plan le otorgó a los colegiales de San 
Bartolomé, cierto grado de autonomía interna, pues podían intervenir en las oposiciones de los catedráticos. Los colegiales del Rosario tuvieron un mayor grado de autonomía interna, administrativa y financiera, desde la fundación de esa institución, según lo establecido en sus Constituciones. Soto Arango concluyó en esta primera parte que: 1. El origen de la universidad en Occidente estuvo unido al desarrollo de las ciudades. 2. En la península Ibérica se asimilaron los modelos de Bolonia y París, especialmente en las universidades de Salamanca y Alcalá, las cuales se constituyeron en modelos de las universidades creadas en los reinos de ultramar. 3. En el Nuevo Reino de Granada el modelo conventouniversidad fue seguido por los dominicos y franciscanos y el modelo colegio-universidad por los jesuitas y agustinos. 4. La autonomía de estas cuatro universidades menores fue total frente al Estado, pero carecieron de autonomía interna, porque los provinciales nombraban a los rectores y catedráticos, sin consultar al claustro de profesores y estudiantes. 5. Después de 1767, con la Ilustración, la universidad perdió su autonomía frente al Estado, pero ganó en libertad académica, gracias a la secularización, se estableció el estudio de las ciencias útiles y se abandonó la escolástica. 6. Lo relevante de los catedráticos del siglo XVIII fue la defensa que realizaron por enseñar lo que consideraban el pensamiento avanzado de su época.

La segunda parte del libro trata sobre las reformas propuestas por cuatro educadores criollos, neogranadinos e ilustrados, a la universidad, en el Nuevo Reino de Granada. Estos educadores los clasifica la autora en tres generaciones sucesivas. La primera generación incluye personas que nacieron antes de 1750 y comenzaron su vida pública hacia 1760 . Se educaron en Santafé, eran monárquicos y católicos. En su época se comenzó el estudio de los recursos naturales del virreinato. El seglar más representativo de esta generación, elegido por la autora, fue Moreno y Escandón, quien en su plan de reforma universitaria incluyó la secularización de la universidad, la creación de la universidad pública y un plan de estudios con nuevas asignaturas y métodos de enseñanza, para ayudar a formar la identidad americana.

A la segunda generación pertenecen aquellos educadores que nacieron en la década de 1750 y comenzaron su vida pública hacia 1770. Son monárquicos, católicos y no apoyaron abiertamente el movimiento independentista. La autora escogió al sacerdote Juan Eloy Valenzuela y al seglar José Félix de Restrepo, como representantes de este grupo. Los educadores de la tercera generación nacieron después de 1765 y comenzaron su vida pública alrededor de 1790. Se formaron dentro del pensamiento ilustrado, monárquico y católico, pero se vincularon a la 
lucha por la independencia. La autora seleccionó a Francisco Antonio Zea, como su prototipo.

La Ilustración fue el punto de encuentro de Moreno, Valenzuela, Restrepo y Zea. Los cuatro coincidieron en que la razón debía primar sobre la escolástica porque ésta "impedía los estudios útiles y la experimentación sustentada en la razón" y la consideraron como "la madre de todos los males" que aquejaban al país. Los cuatro expusieron en sus planes de reforma la necesidad de conocer el territorio y desarrollar una identidad de nación y de patria. El conocimiento del país implicaba el estudio de las ciencias útiles como la historia, la geografía, las ciencias naturales, botánica, zoología, química, física, óptica, electricidad, hidráulica, astronomía, geología, mineralogía, meteorología, agricultura, industria, comercio y estadística, para identificar, explotar y comerciar las riquezas forestales y minerales del país y hacerlo progresar. Por eso propusieron nuevos autores, textos y contenidos para la cátedra de filosofía, por ejemplo: Isaac Newton, Fortunato de Brescia, Christian Wolff, Melchor Cano, Claudio Fleury y Georges Louis Leclerc Buffon. Además hicieron énfasis en consumir productos nacionales relacionados con el vestido y la alimentación de los estudiantes.

Para estos cuatro criollos, reformadores e ilustrados la universidad debía estar bajo el control del Estado y administrada por los civiles, es decir, que la universidad debía ser oficial, secular o laica, sometida al real patronato. La Corona intervendría en su gobierno, la financiaría con recursos de la Real Hacienda y allí se formarían los funcionarios del Estado. Este proceso de secularización y creación de la universidad pública se originó con la expulsión de los jesuitas y el control de la Corona sobre las universidades, para reformar los estudios universitarios, incluyendo la enseñanza de las ciencias útiles, como un medio de desarrollar estos territorios. Los cuatro planes de reforma universitaria incluyeron un mayor grado de autonomía interna para estas instituciones, porque otorgaron atribuciones al claustro de profesores y estudiantes, en la selección de catedráticos y directivos, como estaba establecido en las universidades de Salamanca y Alcalá, llegando inclusive al extremo de la secularización, al eliminar la posibilidad que los religiosos pudieran asumir la dirección o las cátedras en la universidad pública.

La autora concluye en esta segunda parte que: 1. La autonomía interna y externa es inherente a la universidad desde sus orígenes en el Medioevo. 2. La universidad tuvo que luchar por su autonomía frente a las autoridades civiles y eclesiásticas. 3. Las tres generaciones de educadores criollos, neogranadinos e ilustrados tuvieron en común su catolicismo y fidelidad 
al rey. 4. Estuvieron a favor de la secularización de la educación, la universidad pública y la introducción de asignaturas útiles para conocer y aprovechar económicamente los recursos naturales del territorio y fomentar la identidad nacional y la construcción de la nación colombiana. 5. Se opusieron a la escolástica. 6. La Corona entendió que los nuevos estudios fomentaban las ideas independentistas y por eso eliminó la legislación uniforme que había para las universidades de la península y sus reinos de ultramar. 7. Los virreyes estuvieron a favor de la enseñanza de las ciencias útiles, para obtener un mayor desarrollo de los territorios que administraban. 8. La élite criolla asimiló la idea que este territorio les pertenecía y por consiguiente tenían todo el derecho a gobernarlo. Después que lograron la independencia, se dedicaron a organizar el Estado nacional colombiano y continuaron con la reforma educativa, que privilegiaba el estudio de las ciencias útiles en la universidad pública, pero muchos de estos proyectos se quedaron escritos, sin pasar a la práctica, o su aplicación fue efímera, apenas el tiempo que duró la administración que los impulsó, porque los continuos cambios de gobierno impidieron la continuidad de los planes y políticas educativas. 9. Finalmente la autora invita a "trabajar por la universidad colombiana y latinoamericana... para que se llegue a una universidad nacional, científica e incluyente, construida desde un pasado histórico-cultural común, que permita la soñada identidad latinoamericana".

Antonio José Galvis Noyes Universidad Pedagógica y Tecnológica de Colombia Escuela de Ciencias Sociales 
SOTO ARANGO, Diana Elvira; PANIAGUA, Jesús; LIMA JARDILINO, José Rubens; VERA DE FLACHS, María Cristina. (2011): Educadores Latinoamericanos y del Caribe. De la colonia al siglo XIX y XX, Tomo III. Tunja, León, Sao Paulo, Ouro Preto, Quito, Táchira, San Carlos de Guatemala, Córdoba. COLCIENCIAS, Universidad Pedagógica y Tecnológica de Colombia, DIN, RUDECOLOMBIA, Universidad de León España, Universidad Nove de Julho. Universidad Federal de Ouro Preto, Brasil, Universidad Nacional de Córdoba, Argentina, Universidad de Cuenca, Ecuador. Universidad de Los Andes, Venezuela, Universidad de San Carlos de Guatemala, SHELA- HISULA, ISBN: 978-958-660-178-8, p. 384.

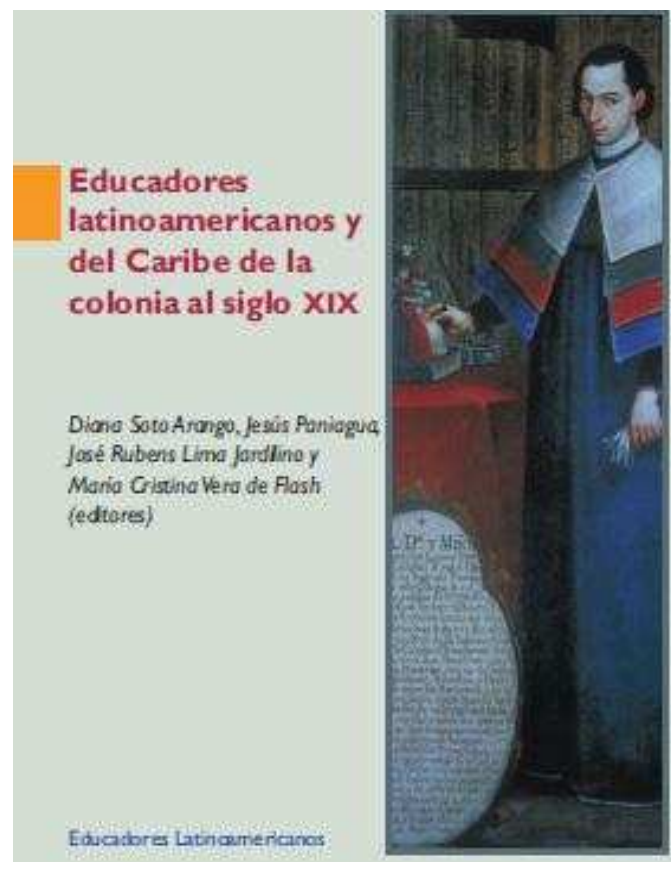

Me corresponde el honor de reseñar el tomo III de la Colección Educadores en América Latina y el Caribe. Siglos XVI a XXI". En primer lugar, se debe anotar que esta época señala la transición entre el virtual monopolio ejercido por la Iglesia en el terreno de la educación, y la adopción de una postura de apertura de parte de la Corona, favorable a la introducción de los contenidos ilustrados al interior de las aulas, y, eventualmente a la creación de universidades públicas. Es decir, se parte de una concepción de universidad que se arraiga en las tradiciones de la universidad medieval, con paradigmas centenarios en las disciplinas aceptadas filosofia, teología, derecho- hacia una universidad donde se van introduciendo los postulados científicos y las nuevas tendencias humanísticas.

En este tercer volumen, en el cual se recoge la participación de 18 educadores de 14 países de América Latina, el escrutinio comienza con la figura de dos criollos, Francisco Antonio Moreno y Escandón, de la Nueva Granada, y Liendo y Goicochea, costarricense que actuará desde la Universidad de San Carlos de Guatemala. En ambos educadores, la perspectiva se centra en torno a intentos reformistas que involucraron 
la enseñanza de las nuevas disciplinas, como en el caso del último de los mencionados, o en la campaña en favor de la apertura de una universidad pública, labor que estuvo liderada por Moreno y Escandón. Al lado de las propuestas de estos innovadores, las comunidades religiosas adoptaron diferentes posturas. Los dominicos, por ejemplo, se situaron resueltamente al lado de la escolástica, en tanto que miembros de otras comunidades, como los agustinos, con Fray Diego Padilla, no vacilaron en ponerse a favor de la divulgación de los saberes modernos.

Ya en tiempos de la República, la educación constituye el eje en torno al cual los diferentes gobiernos de las nacientes repúblicas articularon los discursos alrededor del progreso y en lucha contra la ignorancia. En el caso del Cono Sur, por ejemplo, figuras como las de Sarmiento y su seguidor Varela, al lado de Juana Manso, jalonaron esos esfuerzos, alimentados por la influencia de figuras de la pedagogía clásica como Pestalozzi y Froebel. Al lado de estos educadores también se deben mencionar representantes de tendencias más modernas. Así, la escuela activa, promovida por Froebel, está representada por el peruano José Antonio Encinas, el paraguayo Ramón Indalecio Cardozo, y también, nada menos que por el cubano José Martí. Para ellos la formación de las nuevas generaciones debía ser de carácter práctico y técnico.

No se desconoce la influencia ejercida por la mujer en la educación en este período en el cual no podemos dejar de evocar la huella dejada en el imaginario colectivo por figuras tan entrañables como las de las maestras urbanas y rurales. Entre las educadoras mencionadas existen algunas que defienden una postura tradicionalista como la cubana María Luisa Dolz, la dominicana Salomé Ureña o la colombiana Soledad Acosta de Samper. Las tendencias progresistas están encarnadas por la brasileña Nisia Floresta, traductora de los derechos de la mujer que había propugnado Mary Wollstonecraft.

Sea esta la oportunidad para agradecer a los investigadores que intervinieron en la elaboración de este texto, al Comité Científico Internacional, equipo formado por 61 investigadores, que se ocupó de la evaluación de los trabajos presentados, a los doctores Pascual Mora, María Cristina Cárdenas y Jorge Rodríguez Martínez, quienes en Venezuela, Ecuador y Guatemala, respectivamente, asumieron el compromiso de editar este tomo.

Finalmente, hacemos extensivos estos agradecimientos a Diana Soto Arango, desde Tunja, Colombia, Jesús Paniagua, desde León, España, José Rubens Jardilino, desde Ouro Preto, Brasil, María Cristina Vera de Flachs, desde Córdoba, Argentina. Ellos representan los pueblos indígenas, negros, mestizos y blancos de nuestra América.

Jorge Tomás Uribe Ángel Universidad Pedagógica y Tecnológica de Colombia Grupo de Investigación IL AC 
SOTO ARANGO, Diana; PANIAGUA, Jesús; LIMA JARDILINO, José Rubens; VERA DE FLASH, María Cristina. (2011): Educadores latinoamericanos y del Caribe del siglo XX alXXI. Tomo IV. Tunja, León, Sao Paulo, Ouro Preto, Quito, Táchira, San Carlos de Guatemala, Córdoba. COLCIENCIAS, Universidad Pedagógica y Tecnológica de Colombia, DIN, RUDECOLOMBIA, Universidad de León España, Universidad Nove de Julho. Universidad Federal de Ouro Preto, Brasil, Universidad Nacional de Córdoba, Argentina, Universidad de Cuenca, Ecuador. Universidad de Los Andes, Venezuela, Universidad de San Carlos de Guatemala, SHELA- HISULA, ISBN: 978-958-660-179-5, p. 389.

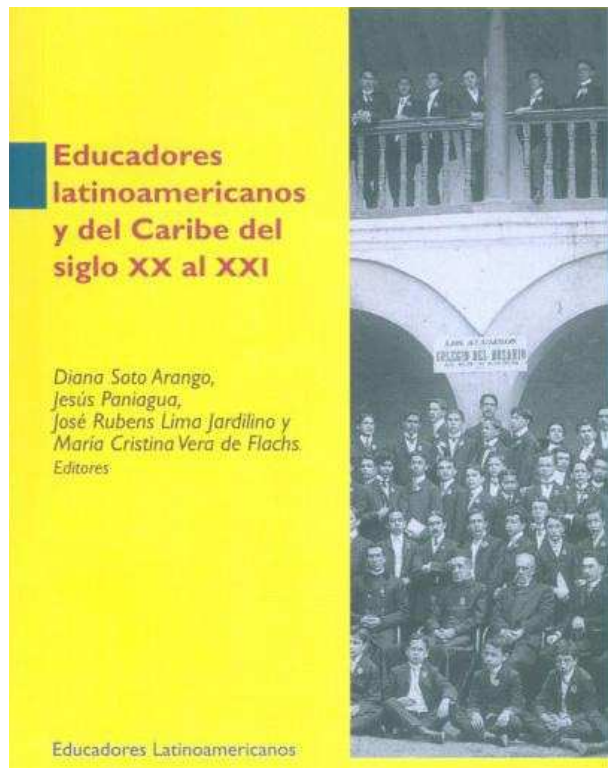

La Facultad de Ciencias de la Educación, en su Escuela de Postgrados se complace en presentar a la comunidad académica, el tomo IV del libro EDUCADORES LATINOAMERICANOS Y DEL CARIBE DEL SIGLO XX AL XXI, el cual es un producto de investigación del proyecto titulado Educadores de América Latina y el Caribe, inscrito en COLCIENCIAS y realizado al interior del grupo HISULA - UPTC.

En este libro, se dan a conocer las acciones sociopolíticas y educativas de los maestros como actores sociales en un contexto local, nacional e internacional. Se fundamenta sobre un constructo teórico interdisciplinario y se orienta principalmente por la historia de las ideas en el campo de formación de formadores. Es decir, este libro dibuja de una manera clara cómo los educadores contribuyeron en el proceso de construcción de nación, sus prácticas pedagógicas, el aporte histórico y las concepciones educativas que aportaron en el ámbito de la historia de la educación. En Educadores Latinoamericanos y del Caribe del Siglo XX alXXI, se destacan 14 educadores procedentes de 8 países de América Latina y el Caribe. El trabajo de investigación y selección apuntó a resaltar el papel de las educadoras invisibilidades en la historia. Este tomo analiza a cinco e incluye una reseña biográfica de 16 más procedentes de 12 países latinoamericanos y del Caribe. 
El primer trabajo corresponde a la Educadora argentina ROSARIO VERA PEÑALOZA, quien se destacó por su preocupación en la reforma educativa, la creación de Jardines de Infantes como instituciones integrales, útiles, necesarias, imprescindibles e insustituibles. Se propuso la tarea de difundirlos e instalarlos en cada rincón de Argentina. Su inspiración teórica fue Federico Froebel y Montessori, Decroli, Montessori y Agazzi. De igual manera, cuenta con un capítulo dedicado a GABRIELA MISTRAL, LA MAESTRA DE ESCUELA, PREMIO NOBEL DE LITERATURA. Gran poetiza y prosista de esta Nuestra América Mestiza. En palabras del Doctor Javier Ocampo López: "Se le conoce en el mundo de la educación al enfatizar en la trilogía educativa de maestros, alumnos y padres de familia en una escuela abierta y comprometida con su contexto social". Para Gabriela Mistral, el niño era el centro del proceso educativo y el método que mejor se adecuaba para la enseñanza era la pedagogía activa. Su defensa por los derechos de la mujer y del niño se transmitió al mundo en un momento de crisis e hizo reflexionar sobre estos temas, que se convirtieron en política internacional a mediados del siglo XX. Ello señala la trascendencia de Gabriela Mistral en la Historia de la Educación Latinoamericana, como una maestra de escuela de grandes méritos, que por el manejo del idioma en su bella prosa y poesía castellana, alcanzó el Premio Nobel que la llevó a la cúspide de las letras en la cultura universal. Otra maestra, que se destacó en el siglo XX fue Paulina Gómez Vega. Una de las muchas mujeres que, desde diferentes roles, ayudó a construir el contexto adecuado para la consecución, defensa y ejercicio de los derechos ciudadanos de la mujer en Colombia. En palabras de los autores del artículo Patricia Triana Rodríguez y Esneider Agudelo Arango, el trabajo de Paulina Gómez Vega se centró en la sensibilización y toma de conciencia para que las mujeres pudieran ejercer el derecho a votar y a educarse. Tomó como consigna el "formar la mentalidad de paz en vez de la mentalidad de la guerra".

Del mismo modo, y con el fin de visibilizar y analizar un sector de la población colombiana, como es la maestra rural en contextos vulnerables y de exclusión social, la Dra. Diana Elvira Soto Arango presenta un estudio sobre dos maestras de escuela en su desempeño docente, que impactaron en unos espacios de poder local, atravesado por el conflicto de la violencia de la década de los años cincuenta del siglo XX en Colombia. En este sentido, el artículo concluye que la labor educativa traspasó las relaciones de enseñanza aprendizaje para presentar un impacto social, con su ejemplo de vida, de valores humanos de solidaridad y tolerancia. Como complemento, el libro EDUCADORES LATINOAMERICANOS Y DEL CARIBE SIGLO XX AL XXI, presenta un amplio resumen de biografías de Educadoras en América Latina y el Caribe siglo XX, como 
son: Raquel Camaña (1883-1915) y Herminia Brumana (1897-1954), Argentina. Deolinda Daltro (... 1935), Brasil. ELFFY ALBRECHT IBÃNEZ (1914-1987), Bolivia. María Isabel Carvajal (1887-1949), Costa Rica. Guadalupe Larriva (1956-2007), Ecuador. María Lavalle Urbina (1908-1996), México. Benita Adelivia Castillo Lanuza (1896-1988), Guatemala. Tomasina Ester Casís (1878-1962), Panamá; Serafina Dávalos (1883-1957), Paraguay; Concha Meléndez (1895-1983), Puerto Rico y Julia de Burgos (1914-1953); Camila Henríquez Ureña (1894-1973), República Dominicana; Leonor Horticou (1872-1941), María Vittori (1874-1959) y Alicia Goyena (1897-1977) Uruguay.

De igual manera, este tomo IV no podía dejar de lado a estos grandes educadores de América Latina como: JOSÉ VASCONCELOS (1882 1958), quien sentó las bases institucionales para el futuro del desarrollo de la educación en México. Renate Marsiske, la autora del artículo dice: Vasconcelos estaba seguro que el único camino para México de lograr el status de una nación capitalista moderna, era incorporar al pueblo de México, y muy especialmente a los indígenas, a la civilización moderna y esto solo se lograba por medio de la educación. Para él, el México del futuro sería un México de mestizos, en su mayoría de clase media, con una cultura propiamente mexicana para todos. Esta cultura mexicana había que desentenderla de las ideas partidistas y de las ideas americano - europeizantes así como de la idea hispanista y conjurar lo mejor de ambas en la búsqueda de una identidad propia, que sirva de orientación a la educación mexicana. Uno de sus libros más conocidos LA RAZA CÓSMICA, MISIÓN DE LA RAZA IBEROAMERICANA. NOTAS DE VIAJE A LA AMÉRICA DEL SUR.

En otro ámbito latinoamericano, el educador FRANCISCO GARCÍA CALDERÓN REY (1883-1953) un peruano de la generación del "novecientos", pensaba en la realidad social, la identidad, el destino hispanoamericano, el análisis de la cultura europea junto con la política internacional de su tiempo. Con la iniciación del novecientos, el pensamiento hispanoamericano pasaba de una etapa de imitación a un período de búsqueda de la propia identidad y desarrollo creador. ARIEL, el encendido manifiesto de Rodó (1900), ofrecía una eventual alternativa a la pauta de progreso material del mundo anglosajón, destacando el papel de las ideas y las posibilidades de la raza hispánica en la perspectiva de un engrandecimiento continental. En las propuestas de muchos intelectuales, más allá de la dirección que tomarán, la idea de la élite pensante estaba el sentido rodoniano, compartido por RUBEN DARÍO (NICARAGUENSE), José Vasconcelos (mexicano), Pedro Manuel Arcaya (venezolano), Carlos Arturo Torres y Guillermo Valencia (Colombianos), 
la mayoría de ellos reconocían el liderazgo intelectual de José Enrique Rodó. Quien al fallecer, dejó a FRANCISCO GARCÍA CALDERÓN REY como el indiscutido capitán general de los pensadores del Nuevo Mundo Hispánico, como lo arfima Teodoro Hampe Martínez en este su artículo.

Desde Argentina, la Pedagogía biopolítica de Saúl Taborda constituye un intento particularmente original y lúcido de articular pedagogía y política en tiempos de profunda transformación histórica y también, de situar problemáticas que plantean ambas disciplinas sobre el horizonte de sentido desde lo particular. TABORDA piensa la nación como un ámbito dotado de una politicidad originaria (respecto de la cual el Estado realiza una politicidad derivada e impropia) y piensa la vida en común por fuera del cauce racionalista y racionalizador que provee la sociedad civil (y civilizada, en el sentido negativo sometida a un módulo cultural heterónomo y abstracto, desvitalizado, como lo plantea Carlos A Casali en su artículo. Así mismo, desde Colombia Agustín Nieto Caballero, Pensador de la Educación y la cultura colombiana se consagró como líder de la pedagogía activa y su mayor aporte está relacionado con la escuela nueva, como modelo pedagógico y didáctico con aspectos de su propia creación, útil en la formación de los nuevos ciudadanos colombianos que formó los líderes, especialmente para la segunda mitad del siglo XX. Como lo explica muy bien la autora del artículo Dra. Myriam Báez Osorio, el pensador colombiano Agustín Nieto Caballero propuso un modelo de escuela nueva con un plan de estudios racional animado de enseñanzas vivas que movieran el interés de los alumnos y los disciplinara. Aspectos que puso a prueba en el Gimnasio Moderno y luego en el Gimnasio Femenino, instituciones que él creó y desde las cuales irradió su pensamiento para América. Para él, la Universidad debía ser la principal gestora de la nación, llegar al pueblo y acercarse con ideales de progreso, pues la misión de la Universidad era formar hombres reflexivos, dinámicos, trabajadores, capaces de emprender con voluntad y espíritu generoso acciones que fueran de empeño nacional y que el Estado requería.

Por su parte el Doctor Álvaro Acevedo Tarazona presenta al Educador Boyacense JORGE ROA MARTÍNEZ, un político y visionario que logró trascender los límites de su pueblo natal Guateque. En su vida como hombre público Roa Martínez se mostró fiel a unos principios de servicio y entrega a lo que él consideró que debía ser el Estado moderno8. Sus tempranas preocupaciones y querellas por lo que implicaba tomar conciencia de las riquezas naturales del país -el petróleo, el carbón9-; su participación en agrupaciones como la Sociedad de Ciencias Naturales del Instituto de La Salle; sus críticas sin ambages al clientelismo y la 
corrupción que observaba como parte de las prácticas políticas de un gobierno centralista; sus llamados a modernizar las instituciones públicas y a fortalecer el Estado a través del cobro de impuestos que permitieran apropiar recursos que luego pudieran ser revertidos a las comunidades -que, una vez organizadas, empezaran a reclamar una mejor calidad de vida-, descubren en él la vocación de un Centenarista y el talante de un cosmopolita, tocado por los vientos de renovación de un mundo vanguardista, que intenta sobreponerse a los estragos de la guerra. La vida y obra de Jorge Roa Martínez se enlazó con la historia de Pereira, del civismo y de la educación, su figura se convirtió en un ícono. Roa Martínez dejó una huella imborrable en la historia de la ciudad de Pereira no sólo por el proyecto universitario del cual había sido su principal artífice sino por las múltiples obras urbanas y culturales como Alcalde y miembro del Tribunal Superior de la Sociedad de Mejoras y del Club Rotario de Pereira. Fue Roa Martínez un intelectual, un humanista, un hombre de acción, pragmático y de convicciones sociales y políticas fieles a un ideario cívico y cultural. La muerte de Roa Martínez acaeció en una etapa de profundas transformaciones urbanas en Pereira, muchas de ellas fruto de su esfuerzo y espíritu visionario.

Era tal el inventario de realizaciones en el decenio de los sesenta en la ciudad, que entre los años de 1966 y 1968 se contaban con orgullo las siguientes: la Universidad Tecnológica de Pereira, la construcción de la Villa Olímpica, la puesta en marcha del Zoológico Matecaña, la creación del Bolívar desnudo y la celebración del Centenario (1963), la sede del Suramericano de Pesas (1963), la construcción del Coliseo Mayor y del Terminal de Transportes, la creación del departamento de Risaralda (1966) y la fundación de la Universidad Libre (1968). En el campo educativo no eran menores las realizaciones con la creación de centros tanto públicos como privados: Escuela Carlota Sánchez (1960), Escuela Juan XXIII (1961), Colegio Rafael Uribe Uribe (1963), Escuela Hans Drews Arango (1965), Escuela Atanasio Girardot (1965), Colegio Jesús María Ormaza (1966) y Colegio Alfonso Jaramillo Gutiérrez (1966), entre otros. También se propuso la creación de una universidad exclusiva para mujeres. Éstas y otras obras habían surgido de iniciativas propias y sin ayudas oficiales.

JUAN MANTOVANI. LA EDUCACIÓN COMO CONSOLIDACIÓN DE HUMANIDAD, es un artículo escrito por la argentina Clara Inés Stramiello. La propuesta filosófica de Mantovani reposa sobre los conceptos de formación y de espíritu. Formar para una vida plena implica integrar el mundo individual con el mundo espiritual y objetivo de la cultura, para que el sujeto se apropie de la cultura y a la vez sea capaz de actuar creativamente para producir cultura o para 
modificar la existente. El humanismo de Mantovani se presenta como una vía de solución a la cuestión educativa e incide como modelo normativo en la pedagogía, la didáctica y la política educativa. Es indudable que Mantovani pone el acento de la actividad educativa en la formación de una personalidad integrada con la comunidad. Su humanismo pedagógico es una respuesta a un mundo tecnificado que ha desvirtuado los valores y pondera lo técnico sobre lo ético, lo físico sobre lo metafísico, lo externo sobre lo íntimo. Para él la educación es un fenómeno profundamente humano y un dinámico juego de influencias en el que se conjugan las aspiraciones personales con las circunstancias sociales y culturales.

Desde la Universidad Pedagógica y Tecnológica, el Dr. Carlos Arturo Londoño Ramos, analiza la vida y obra de LUIS BELTRÁN PRIETO FIGUEROA: LÍDER DE LA PEDAGOGÍA ACTIVA. En América Latina Prieto Figueroa, ha sido uno de los pensadores, uno de los líderes y uno de los maestro que más se ha preocupado por apropiar la pedagogía activa en sus diferentes aspectos: filosóficos, sicológicos, políticos, sociales, jurídicos y propiamente pedagógicos, sin embargo no profundizó, propiamente en la epistemología del constructivismo pragmático que se encuentra como fundamento de esta escuela pedagógica. La pedagogía activa, como muestra Prieto Figueroa, ha sido una de las más grandes escuelas intelectuales en América Latina con repercusiones tanto en la teoría como en la práctica y la política educativa. Esta escuela pedagógica está también ligada a una visión filosófica, sicológica y sociológica que nos ha marcado culturalmente tanto por sus logros como también por sus dificultades y fracasos. JUAN JOSÉ ARÉVALO: LA PEDAGOGÍA FILOSÓFICA COMO GUÍA DE LA TRANSFORMACIÓN POLÍTICA, es un artículo del autor Jorge Mario Rodríguez Martínez, de Universidad de San Carlos de Guatemala- Guatemala. Las ideas del pensador y ex presidente guatemalteco Juan José Arévalo gravitan alrededor de las nociones de valores y conciencia y su interés por la axiología, en el seno de una tradición ética hispanoamericana que encuentra en el krausismo una de sus motivaciones principales. Los ideales pedagógicos y filosóficos de Arévalo luchan por lograr la dignificación de la sociedad guatemalteca, erradicar la injusticia y la violencia estructural que ha afectado a este país a lo largo de su historia. En Arévalo se opera la transposición del pensamiento noble del educador hispanoamericano al terreno de la política en su sentido más profundo: como creador de una colectividad. La recuperación del pensamiento de Arévalo se constituye en una tarea importante ahora que las naciones hispanoamericanas pueden cumplir la tarea de educar a los poderosos para un orden global más justo y humano. 
De igual manera, desde la UPTC, el doctorando William Pacheco Vargas hace un trabajo de análisis y síntesis donde da a conocer la vida y obra del maestro ELIÉCER SILVA CELIS: IDEAS EDUCATIVAS Y DIRECTRICES UNIVERSITARIAS EN LA CREACIÓN Y FUNCIONAMIENTO DE LA UNIVERSIDAD PEDAGÓGICA DE COLOMBIA. Dice el profesor Pacheco que al realizar un balance de los resultados de las ideas educativas y directrices universitarias del Dr. Eliécer Silva al frente, primero en la Universidad Pedagógica y luego en la Universidad Pedagógica y Tecnológica de Colombia, en momentos decisivos para su creación y consolidación como la segunda institución de educación superior de orden nacional, a lo largo de diez y siete años, encontramos entre otros que: siendo fiel con su formación recibida en la Escuela Normal Superior en Bogotá, el docente lo es en la medida que investiga en el campo del conocimiento que se desempeña. De ahí, que la estructura de Ciudad Universitaria que proyecto inicialmente, poseía la infraestructura que aseguraba una fecunda labor pedagógica, donde enfatizaba la presencia de los institutos de investigación. No obstante, la primera Universidad Pedagógica, difería del planteamiento inicial, donde los Institutos de formación académica e Investigativa, no quedaban en los mismos predios de la Universidad, sino en diferentes municipios y provincias del departamento de Boyacá, lo que implicaba dificultades para su funcionamiento. En cuanto a los recursos humanos, dificultades de encontrar: directivos, docentes e investigadores; eran el resultado de estar ubicados en una provincia, carente de una élite intelectual suficientemente preparada que la sustentara y del adecuado presupuesto para ofrecer unos salarios suficientemente atractivos. Sin embargo, con su gestión demostró que el educador además de ser investigador en su campo de acción debía superar las dificultades de todo orden cuando tenía que asumir responsabilidades administrativas y de política académica en un centro de educación superior. Su idea de crear un centro esencialmente pedagógico, para la formación profesional e investigativa del profesorado, en todos los niveles y para todas las ramas del conocimiento y la técnica, fue mal entendida por sus contemporáneos; pues no obstante de ser el fundador, organizador y poner en marcha la Facultad de Agronomía, situación que encaminó a la institución hacia la multiprofesionalización y el proceso tecnológico unido al pedagógico en la formación docente, para dar respuesta a la pérdida del protagonismo pedagógico a nivel nacional, buscaba dar solución a los problemas del medio regional y departamental; igualmente, fue contradictorio encontrar las acusaciones al Dr. Eliécer Silva de ser enemigo de las carreras técnicas, cuando precisamente fue él quien inició y terminó la infraestructura del edificio para 26 laboratorios y su correspondiente dotación para las ingenierías existentes, lo que garantizaba que fueran programas sustentados en la investigación y 
autónomos frente a otros centros educativos del país. Finalmente, el Dr. Eliécer Silva Celis, se identificó con la filosofía de la Escuela Normal Superior, como proyecto liberal.

Al igual que otros intelectuales encontraron en la creación de una institución de educación superior de carácter pedagógico en Tunja, la oportunidad para crear el "Modelo educativo para el país". Él quiso ser consecuente con ello, fueron sus esfuerzos de asignarle la dirección de la pedagogía nacional y la misión de ser el órgano asesor del Estado para dar respuesta a los desafíos educativos de la Nación de ese momento, a través de la creación de Institutos Anexos, como centros pilotos de la investigación pedagógica, contando con el apoyo tanto de instituciones nacionales como extranjeras. Finalmente, el profesor Pacheco plantea que no obstante, los resultados no coinciden con los fines y misión trazada para una institución especializada en la pedagogía, al duplicar los esfuerzos tanto en lo pedagógico como en lo tecnológico, explicable que en sus inicios buscara un reconocimiento nacional, pero al perder la tutela del presidente boyacense, dejó de ser un órgano orientador de la educación y pasó a ser una institución que espera ser orientada; posiblemente porque ya no representaba los intereses nacionales, sino regionales de la sociedad colombiana; a pesar de la gestión desplegada por Eliécer Silva Celis. Muestra de ello, es que transcurridos 58 años desde la creación de la Universidad, es el momento que la institución no ha logrado establecer los mencionados institutos de investigación y superar la etapa de profesionalización, para así dar respuesta a las necesidades de la región y del país a partir de la generación de conocimiento socialmente pertinente, menos de su aplicación, posiblemente porque sólo se piensa en reformas en la estructura universitaria donde la academia esté al servicio de las necesidades particulares de la administración del momento. Podemos decir con certeza que el tomo IV EDUCADORES LATINOAMERICANOS Y DEL CARIBE DEL SIGLO XX AL XXI, es un libro que recoge con arte e investigación el pensamiento educativo latinoamericano y sintetiza una postura para el siglo XX y XXI.

Doris Lilia Torres Cruz

Universidad Pedagógica y Tecnológica de Colombia Grupo de investigación lenguajes en educación- LEEN 
BESTANI, Rosa; BRUNETTI, Paulina; MARTÍNEZ DE SÁNCHEZ, Ana; VERA DE FLACHS, María Cristina. (2011): Textos, Autores y Bibliotecas: 190 años de la biblioteca mayor de la Universidad Nacional de Córdoba. Argentina, Universidad Nacional de Córdoba, 688 p. ISBN: 978-987-1498-26-0

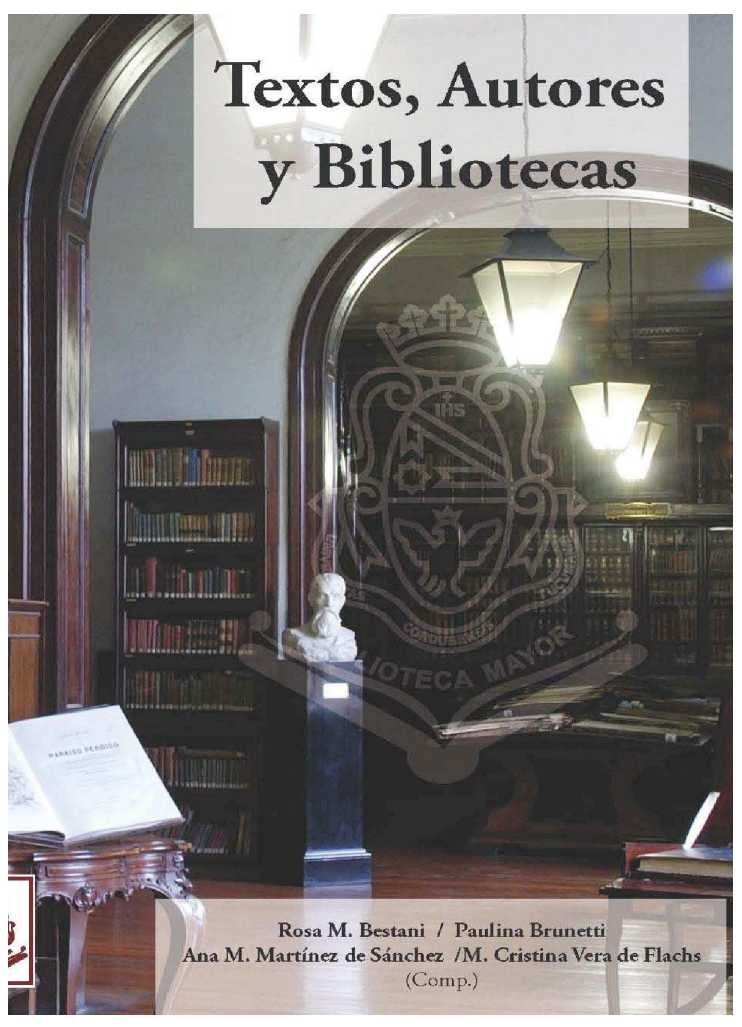

retomar los términos de Paul Ricoeur.
La Ilustración trajo consigo un nuevo instrumento para utilizar en el dictado de las asignaturas: los libros de texto. Durante el reinado de Carlos III se puso en marcha un programa de reformas en las universidades hispanas y a partir de entonces los manuales, tratados o libros de textos comenzaron a circular más asiduamente. En consecuencia, hubo una proliferación de impresos y una mejora de las bibliotecas universitarias, las que debían ponerse al servicio de la docencia y los usuarios. De allí surge "el mundo del texto" y el "mundo del lector" para

A pesar de la importancia que el tema tiene para la Historia de la Educación y en particular para la Historia de las Universidades, el análisis y conocimiento de los manuales de estudio y otros textos de enseñanza que circularon en determinadas épocas constituye una línea de investigación novedosa y menos explorada, particularmente en América Latina. El libro reduce la acción del profesor y del estudiante y abarca la ciencia del momento cuando el mismo fue escrito; de allí que un buen texto nos permite conocer las fuentes de información, los autores consultados y las investigaciones realizadas por el creador. Por lo general, en los primeros manuales universitarios se omitieron las citas de pie con precisión de nombre de autor y lugar de edición como lo exige la crítica moderna. Pero de todos modos ellos descubren nuevos focos del saber, a la vez que sus contenidos permiten conocer cuáles 
eran los autores recomendados o manejados en los recintos universitarios, la difusión de los mismos en regiones recónditas así como descubrir por qué ciertas obras y nombres eran postergados o proscriptos.

El conjunto de investigaciones que conforman el dossier Manuales $y$ textos universitarios, que está inserto en el libro Textos, Autores y Bibliotecas, reúne aportes de profesionales de diferentes procedencias disciplinares y académicas interesados en esclarecer las transformaciones de la problemática a lo largo de los siglos XVIII al XX. En efecto, es posible constatar en ella la presencia de autores provenientes de universidades nacionales (Buenos Aires, Rosario y Córdoba), españolas, mexicanas, colombianas y, en particular de un grupo de brasileros que nos ofrecen sus conclusiones haciendo hincapié en la realidad de su país y de Portugal. Los artículos han sido ubicados por estricto orden alfabético, sin embargo en esta presentación los agrupamos cronológicamente y los dividimos en los que hacían referencia al nivel universitario y otros textos de enseñanza, los que nos permiten tener conocimiento sobre lo que se estudiaba en la época analizada en otros niveles.

Llevado a un terreno particular, los autores que siguen a continuación se preocuparon por medio de estudios de casos analizar la temática sobre las grandes ramas en que se descompone la enseñanza superior en las casas de altos estudios argentinas y extranjeras. Celina A. Lértora Mendoza se ocupó de la penetración de la cultura impresa en las sociedades del Antiguo Régimen estudiando el valor de los cursos manuscritos coloniales como libros de texto. Sabido es que en las Universidades, Colegios y Estudios Conventuales coloniales americanos, la práctica del "dictado" fue generalizada. Nunca fue sustituida por la lectura directa de bibliografía impresa, a pesar de la existencia de bibliotecas, algunas bien dotadas como lo demuestra el hecho que muchos profesores, además de "dictar" aconsejaran el uso de bibliografía complementaria. En síntesis, señala que los cursos dictados comparten con los libros las siguientes características: 1.) Su carácter obligatorio y básico para la aprobación de la materia; 2.) Representan el modo personal como el profesor quiere estructurar la disciplina y los contenidos; 3.) Genera una tradición académica, que se documenta por los traspasos y 4.) Es un recurso más rápido y económico, al alcance de cada uno de los cursantes.

Marcela Aspell nos informa sobre la creación de la Cátedra de Instituta en la Universitas Cordubensis Tucumanae y el material de enseñanza que poseía su primer profesor haciendo hincapié en el texto de Arnold Vinnius, recomendado a los estudiantes. Cristina Cárdenas Castillo se propuso identificar los textos utilizados en la educación superior de Guadalajara México - desde 1835 hasta 1899. A lo largo de este período la enseñanza fue impartida en dos establecimientos: La Real Universidad de Guadalajara -de origen y estructura colonial- y el Instituto de Ciencias del Estado de 
Jalisco -de filiación liberal-. En conjunto, estas dos instituciones utilizaron 130 autores -algunos de ellos con varios títulos: La autora señala los aportes de este corpus a la comprensión del liberalismo decimonónico, de las redes que ligan el avance científico a la producción de libros y a la concepción y estructura de los planes de estudio.

Cristina Vera de Flachs abordó el tema de los saberes cultivados en las tres Facultades existentes en la Universidad de Córdoba en el último tercio del siglo XIX, época en el desarrollo científico alcanzó gran desarrollo y de él da cuenta a través de una selección de textos y manuales utilizados en cada una de ellas. En sus comienzos, los programas de estudio fueron copias, imitaciones o adaptaciones, con escaso criterio nacional, de los extranjeros. Por eso algunos opinaban que era más sencillo realizar una modesta traducción de textos ya probados que acometer la confección precipitada y comercial de autores que todavía necesitaban formarse. De allí que varios de los mencionados fueron fruto de traducciones de los recomendados en universidades europeas pero, en otros casos, fueron producto del trabajo intelectual de sus profesores. De hecho hubo varios de baja factura pero, otros, suponían una verdadera ruptura con el pasado y una apertura liberal, en tanto modificaban conceptos atrasados y presentaban los resultados de una ciencia que pretendía entrar a la modernidad.

Silvia Longo presentó un libro técnico que ocupó el tradicional lugar del manual de arquitectura, editado en 1936 en Alemania donde se agotó inmediatamente. Las traducciones reafirmaron mundialmente un fenómeno editorial singular y sostenidas reediciones lo posicionan, aún hoy, como uno de los textos más consultados en escuelas y bibliotecas institucionales. El autor, Ernst Neufert (profesor y director del Departamento de Construcciones de la Escuela Bauhaus de Weimar y luego director y responsable del Taller de Arquitectura de la Universität Jena) intentó actualizar y sistematizar el proyecto de programas modernos y divulgar normas de la nueva arquitectura. Los principales argumentos formulados desde las diferentes sedes de las vanguardias europeas de posguerra (existenz-minimun, standarización, industrialización, racionalismo, funcionalismo) fueron recopilados en "el Neufert" según nuevas expresiones normativas: con una minuciosa estrategia de comunicación que organizaba uniformemente los temas y una gráfica abundante que condensaba los tamaños de todas las cosas del mundo moderno.

Teresa de Sierra Neves realizó una valoración crítica y un reconocimiento del papel hegemónico que tuvo la "Teoría de la dependencia" en el pensamiento social latinoamericano. La misma se expresó en los contenidos de los programas de las asignaturas de las ciencias sociales que se impartían en esas décadas en las universidades públicas, como también en las corrientes de pensamiento, análisis de la realidad latinoamericana y movimientos 
sociales de ese entonces, de los que no estuvo exenta la Argentina. Desde España, Isabel Lafuente se ocupó de analizar la enseñanza de la Filosofía en España tomando como punto de inflexión la instauración de la Democracia a partir de 1976 y el uso de los textos y manuales universitarios de filosofía en España. Lo que la lleva a preguntarse: ¿filosofía española/filosofía en español? y a demostrar los temas, problemas y metodología más actuales en esa asignatura.

Por su parte, Juan Ramón Álvarez, nos introdujo en la metodología de la ciencia destacando la importancia de algunos tratados, manuales y textos de estudio entre los que menciona a Karl Popper, Thomas Kuhn y el argentino Mario Bunge, concluyendo que el panorama resultante es variopinto y que los manuales de metodología no son siempre generales. Muchos de ellos son de una sola ciencia o de determinadas clases de ciencias: naturales, sociales, etc. A su criterio, temáticamente deberían recoger en sus campos todo lo que reune el gran libro de Bunge, prácticamente sin excepciones. También señaló que la dificultad de distinguir entre tratados y manuales reside en que es una distinción de uso más que de contenido.

Concluido este enfoque, resulta interesante destacar las propuestas presentadas por los autores que se preocuparon por explicitar la importancia de los textos que modificaron la cultura escolar en Brasil, Portugal y Colombia. Desde Brasil, Gladys Mary Ghizoni Teive investiga los presupuestos de la Reforma de Orestes Guimarães (1911-1935) en la cultura escolar de la Escuela Normal Catarinense), reforma que modificó radicalmente a la escuela pública en sus saberes, normas y prácticas. Gilberto Luis Alves y Carla Villamaina Centeno intentaron con su investigación aprehender las interpretaciones respecto a la Guerra de la Triple Alianza (1864-1870), así como sus fuentes a lo largo del tiempo, por medio del discurso de los manuales didácticos del área de Historia de Brasil. De dicho análisis extraen las siguientes conclusiones: 1) los manuales didácticos, cuanto a sus fuentes, se limitaron a incorporar la interpretación de los historiadores militares; 2) redujeron la descripción del conflicto a sus causas diplomáticas y a sus embates armados; 3) del punto de vista epistemológico, su discurso es positivista; 4) la concepción y la forma de organización de esos manuales exigían del estudiante, sobretodo, la memorización de las informaciones y, 5) fruto de una incipiente división del trabajo didáctico, tales instrumentos ya denotaban la instauración del proceso de simplificación y objetivación de la actividad del profesor.

Claudemir de Quadros nos ofrece un análisis de los boletines del Centro de Pesquisas e Orientação Educacionais - CPOE/RS - órgano vinculado a la Secretaría de Educación del Estado de Río Grande do Sul/Brasil que, entre los años de 1943 y 1971, participó de propuestas y ejecutó políticas públicas y reformas educacionales. Es interesante resaltar que dichos boletines 
reúnen otros textos como comunicados, ofícios, instrucciones, noticias y orientaciones que tuvieron circulación en los medios comunicacionales del mencionado Estado. Finalmente, cabe reafirmar que los discursos producidos por el CPOE/RS, deben ser leídos desde una perspectiva que envuelve la modernidad pedagógica más racional.

María Helena Cámara Bastos centró su estudio en un análisis de los manuales para orientar los estudios en la historia de la pedagogía y \o de la educación, aprobada en las escuelas normales y universidades han contribuido a la formación del campo en Brasil. Cree que estas obras sirvieron como modelo para los programas de disciplina y de los libros de historia de la educación pública de su país en la primera mitad del siglo $\mathrm{XX}$. Teniendo en los manuales como instancias de producción y circulación del conocimiento en una disciplina o campo de conocimiento, es posible identificar las continuidades y las marcas que siguen definiendo la disciplina en cursos de formación para los profesores. Los libros de texto, el contenido y estructura, apuntan a una tradición de medidas disciplinarias en el último siglo y aún hoy: cronológico y lineal de vista de la historia, sobre todo una historia de las ideas pedagógicas y pensadores, y en el marco de la historia política de la sociedad, una perspectiva comparada, y también estudios de educación comparada, una concepción positiva de la sociedad, el papel redentor de la educación y el maestro.

Los profesores Alice Yoko Horikawa y José Rubens L. Jardilino en os textos escolares - o livro didático no Brasil: políticas de avaliação e de controle dos saberes escolares se propusieron demostrar que son muchos los intereses que cercan, hoy día, la producción del libro de texto (manuales didácticos) en Brasil asociado con la formación de maestros (formación inicial y continua). Por medio de un transfondo histórico, reflexionaron sobre una experiencia de evaluación de libros de textos (manuales didácticos), realizada por el Ministerio de la Educación de Brasil, movilizados por el objetivo de mostrar cómo ese proceso de evaluación contribuye para mejorar la calidad de la educación ofrecida a la población en general frecuentadores de la escuela básica ofrecida por el Estado brasileño. Esto ha generado por un lado un mercado editorial que, para ampliar su público consumidor, se dedica a producir manuales que procuran ajustar sus proposiciones al tiempo, espacio y condiciones escolares. Y, por otro lado, es precisa la existencia de un grupo de docentes que por diversas razones pautan su actuación profesional a las actividades propuestas por los autores de libros didácticos.

Para conocer en profundidad los manuales escolares y su incidencia en las actividades docentes contamos con la ayuda de los artículos que siguen a continuación. Carlota Boto aborda las prácticas de enseñanza de la moral y de la civilidad en la historia de la escuela portuguesa. Para ello, fueron estudiados 
libros didácticos utilizados en escuelas de Portugal (siglos XIX y XX). Se nota en los textos la existencia de estrategias claras para acoplar - a la enseñanza del leer, del escribir, del contar y de formas de comportamiento. La escuela habla del mundo a los niños; de un mundo para el cual son necesarias algunas sutiles enseñanzas: el aprendizaje del silencio, de la modestia, de la aceptación de lo existente como necesario y de la obediencia como valor en la vida cotidiana. El libro escolar actuaba como protagonista del proceso civilizador. Los compendios escolares trazaban, en el recorrido de la enseñanza, un mapa orientador, una directriz cultural, un vehículo de presentación de lo que en el mundo habría de ser importante. Por medio del libro, el mundo sería contado a los niños, con la intención de formar en ellos el adulto futuro.

Continuando con esta línea de análisis, Diana Soto Arango expone un caso comparativo del uso de manuales con el objetivo central de analizar un tema de relevancia en estos años que se festejan los bicentenarios de las independencias americanas. En "La Independencia americana en los textos escolares de Colombia" la autora compara tres períodos bajo la legislación colombiana y estudia la evolución del tema a través de los mensajes e imágenes que transmiten los textos escolares de ciencias sociales y de historia en la enseñanza de la educación básica primaria y secundaria en el período 1974 a 2008. La pregunta que se formula para explicitar su propuesta es ¿cuáles son los contenidos e imaginarios que se han trasmitido a través de los textos escolares en ciencias sociales sobre la independencia americana y que orientan hacia una nueva identidad en el imaginario de la nación en Colombia en el período de 1974 a 2008? La metodología que aplicó se sustenta en el análisis de contenido de textos escolares dentro de la historia social de la educación que permite ubicar y analizar el contexto legal educativo, autor, texto y editorial. De esta manera el contenido se ubica en épocas y contextos político-educativos que configuran procesos de identidad socio-cultural colombiano a través del tema de la independencia americana.

Para concluir y como cierre de los sustanciosos análisis aportados en esta recopilación, es necesario llamar la atención sobre la importancia del tema en tanto él nos informa sobre el saber impartido en universidades y colegios del antiguo y nuevo régimen. Es de desear que estas reflexiones puedan servir de impulso para posteriores discusiones acerca de problemáticas relacionadas con él y encausar futuras investigaciones dentro del marco de la historia comparada, lo que sin duda será provechoso para superar el provincialismo tan frecuente en nuestro campo de estudio.

María Cristina Vera de Flachs Universidad Nacional de Córdoba Grupo de investigación HISULA 


\section{EDUCERE. La Revista Venezolana de Educación ISSN: 1316-4910. Año 15, N. 50 Enero- Abril 2011. Mérida (Venezuela)}

\section{ÍNDICE}

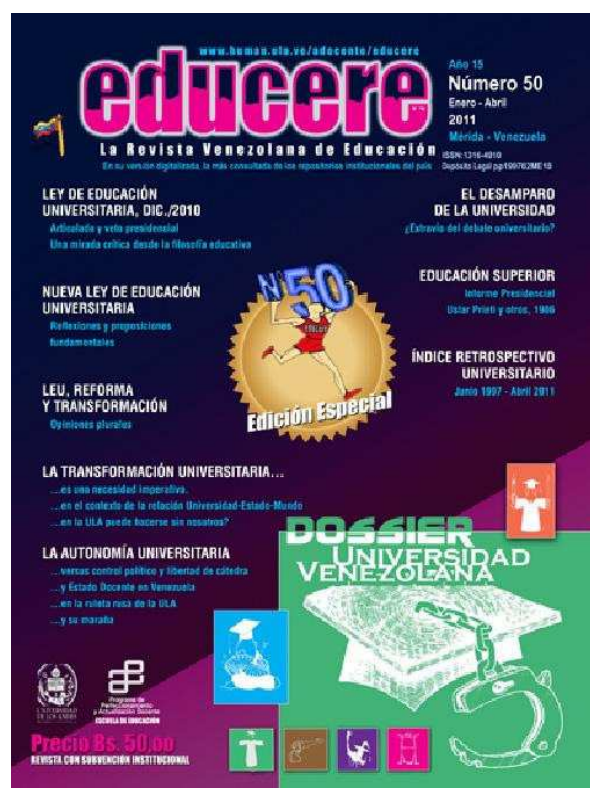

Una Revista en 50 fascículos y una Universidad que fenece o se transforma Pedro Rivas.

Universidad de Los Andes, Escuela de Educación. Mérida, estado Mérida. Venezuela Lista y descarga en línea.

Notas Conmemorativas de Educere Carlos Paladines (Ecuador), Ali Lópezy Marlene Bauste (Venezuela.

La Universidad Venezolana en el marco de la legislación actual Asamblea Nacional de la República Bolivariana de Venezuela.

La carta veto del presidente a la ley de educación universitaria Hugo Chávez Frías.

Ley de educación universitaria 23/12/2010. Articulado Asamblea Nacional de la República Bolivariana de Venezuela.

El desamparo de la universidad: el sentido del debate universitario en el marco de la ley de educación universitaria en Venezuela Alejandro Ochoa Arias.

Universidad de Los Andes. Facultad de Ingeniería. Mérida, Venezuela.

La Ley de Educación Universitaria, 2010: Una Mirada Crítica desde el punto de Vista de la Filosofía de la Educación José Pascual Mora García. 
Universidad de Los Andes. Núcleo Universitario "Rafael Rangel” 'Trujillo, ed. Trujillo. Venezuela sobre la Universidad a propósito de la Ley de Educación Universitaria, 2010

Universidad de Los Andes. Facultad de Ciencias. Mérida, edo. Mérida.

Venezuela

Estado, Universidad y Autonomía: reflexiones en torno a la Nueva Ley de Educación Universitaria

Reinaldo Rojas.

El veto Presidencial a la Ley de Educación Universitaria

Juan Carlos Villegas Febres.....

Proposiciones fundamentales para la Ley de Educación Universitaria

Luis Fuenmayor Toro.

Autonomía Universitaria y Estado Docente en Venezuela: Ley

Orgánica de Educación y Ley de Educación Universitaria

Amado Moreno Pérez:

Autonomía Universitaria y Libertad de Cátedra versus control político en la Historia Venezolana

Leonardo Carvajal.

La maraña de la autonomía universitaria en la Venezuela del siglo XX Jorge Dávila..

Sobre autónomos y autonomías un pre-Texto para hablar de la Universidad y de su reforma

Roberto Donoso Torres....

La transformación Universitaria Venezolana: Una necesidad imperativa

Heriberto R. Gómez. Z

La transformación Universitaria en el contexto de la relación

Universidad-Estado-Mundo

Rigoberto Lanzy Alex Ferguson.

La Universidad Transformada

Myriam Anzola.. 
¿Es posible una transformación Universitaria sin que hayamos cambiado nosotros?

Pedro Rivas.

Golpe no tan suave

Rosa Tristán.

Informe que presenta al presidente de la república, Dr. Jaime Lusinchi, la comisión presidencial del proyecto Educativo Nacional. Caracas, Septiembre de 1986

Arturo Uslar Pietri coordinador.

La Ley de Educación Universitaria: Pronunciamientos y

Opiniones

Autonomía de la ruleta Rusa

Rosa Amelia Asuaje.

Después del terremoto de Japón

Juan Puig.....

Impacto de la Ley del servicio comunitario del Estudiante de Educación Superior en el Núcleo Universitario "Rafael Rangel” 'Trujillo Lidia Ruíz.....

Índice temático Universitario 2011

Rosa Amelia Asuaje, Pedro José Rivas e Iran Rosio Jovito.... 265

Galería de Imágenes de Educere. .284

RESEÑA REVISTA PACARINA

Roberto Donoso Torres. 286

Secciones. 289

Normas para los colaboradores y árbitros......................291

Centros de distribución de educere. 304

Orden de suscripción 


\section{REVISTA PROCESOS HISTÓRICOS \\ ISSN: 1690-4818. Volumen X, N. 19 \\ Enero-Junio 2011. Venezuela}

\section{ÍNDICE}

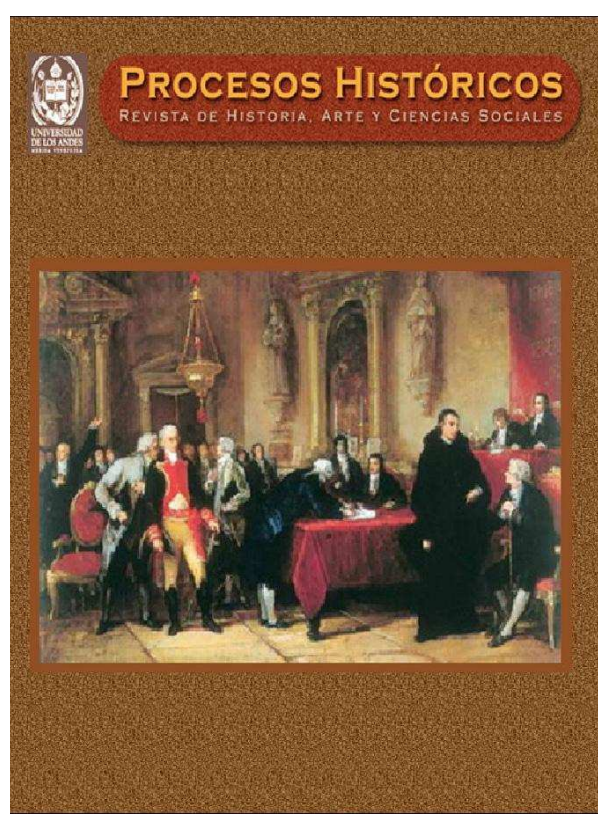

Editorial

Edda Samudio.......................................

Artículos

Demografía histórica en Venezuela: el caso de la mortalidad en Valle de la Pascua durante el gomecismo en Venezuela, 1908-1935.

José Lisandro Contreras Velásquez....2

La ruptura de la proximidad en una sociedad polarizada: el caso del Convento de Santa Clara en Mérida-Venezuela, 1810-1827 Luis Alberto Ramírez. Méndez ........21

Estrategias de inversión y negocios en el contexto agroindustrial azucarero de Tucumán, Argentina (1850-1900). Un análisis de los casos de Wenceslao Posse y la familia Nougués en clave comparada

Francisco Bolsi.

Resguardos indígenas en el Caribe Colombiano durante el siglo XIX Sergio Paolo Solano / Roicer Flórez, Bolivar. .72

Pensamiento educativo de Miguel Acosta Saignes

Magdi Molina Contreras. 96

De la Casa de Estudios a la Real Universidad de San Buenaventura de Mérida de los Caballeros Edda O. Samudio A. 
Documentos.

Documento $\mathrm{N}^{0}$ 1. 1811, agosto 21. Mérida. Consulta que hace el Ilmo. Sr. Santiago Hernández Milanés, Obispo de la Diócesis de Mérida de Maracaibo.

Documento $\mathrm{N}^{\mathrm{O}}$ 2. 1810, septiembre 21. Mérida. Juramento de fidelidad a D. Fernando VII, rey de España y de las Indias, presentado por el Ilmo. Sr. Santiago Hernández Milanés, Obispo de la Diócesis de Mérida de Maracaibo.

Documento $\mathrm{N}^{\circ}$ 3. 1810, septiembre 14. Caracas. Copia del Juramento de fidelidad a D. Fernando VII, rey de España y de las Indias, presentado por el Ilmo. Dr. Narciso Coll y Prat, Arzobispo de la Diócesis de Caracas.

Documento $\mathrm{N}^{\circ}$ 4. 1811, agosto 23. Mérida. Contestación del Pbro. Dr. Mateo José Mas y Rubi, Canónigo y Presidente del Cabildo Eclesiástico, a la consulta del Ilmo. Sr. Santiago Hernández Milanés, Obispo de Mérida de Maracaibo.

Reseñas

Reseña "El Mundo de un Historiador. Antonio Domínguez Ortiz" de Manuel Moreno Alonso

Miguel Angel Rodríguez Lorenzo.....

Reseña "Estudios de Historia Moderna en Homenaje al Profesor Antonio García-Baquero" de León Carlos Álvarez Santaló Miguel Angel Rodriguez. Lorenzo...

Reseña "Introducción a la Historia" de Angel Lombardi Miguel Ángel Rodríguez Lorenzo..........................................................138 